\title{
Hypomagnesaemia As a Mortality Risk Factor in Protein-energy Malnutrition
}

Sir,

Protein-energy malnutrition (PEM) is one of the leading causes of childhood morbidity and mortality in developing countries. The case-fatality rate for PEM was $28.4 \%$ despite hospitalization (1).

Magnesium (Mg) modulates vasomotor tone, blood pressure, and peripheral blood flow. Mg deficiency was shown to trigger vasoconstriction and enhance vascular endothelial injury (2). On the other hand, endothelin-1 (ET-1) is a potent vasoconstrictor peptide, produced by vascular endothelial cells (3). We investigated the effects of hypomagnesaemia on mortality and other mortality risk factors in patients with PEM.

The study included 25 children with PEM. Their mean age was $4.7 \pm 2.9$ months. In the study groups, malnutrition was not related to malabsorption. Malnutrition was diagnosed using the Wellcome classification. All children had severe malnutrition without malabsorption (mean weight-forheight z-score was -3.1). Weights were measured using the same equipment by the same observer. Weights were measured to the nearest $10 \mathrm{~g}$ using a digital electronic instrument (Seca 727 Digital Baby Scale, serial interface RS 232, Seca Corporation, Vogel\&Holke, Germany). Venous blood samples of the children were collected from the antecubital vein for serum $\mathrm{Mg}$, and ET-1 measurements were obtained at admission. Blood samples were immediately centrifuged, separated, and stored at $-80{ }^{\circ} \mathrm{C}$ before analysis. Serum magnesium levels of the 25 surviving and deceased patients were studied by spectrophotometrical xylidyl blue method (Olympus AU2700 autoanalyzer, commercially-available Boehringer Mannheim System kit). Reference range was accepted as 1.71-2.5 mg/dL. ET-1 levels were studied with ELISA method (BioTEK Power-WXS, commercially-available kit; Catalog No. 900-022).

Correspondence and reprint request should be addressed to:

Dr. Zerrin Orbak

Department of Pediatric Endocrinology

Ataturk University Medical Faculty

25240 Erzurum

Turkey

Emal: zerrinorbak@yahoo.com

Fax: +90442 2313564
Mann-Whitney U tests and odds ratio were used for the comparison of means of each group and for ratios of each group respectively.

Informed consent was obtained from parents. The Ethics Committee of the Faculty approved the study.

Serum Mg and ET-1 levels of the patients with PEM were prospectively evaluated. During the follow-up period, four (16\%) patients died within four days after admission. Although serum $\mathrm{Mg}$ levels were significantly lower in the patients who died, serum ET-1 levels were slightly higher at admission (Table). Serum Mg levels were lower than normal value in three (75.0\%) of the four deceased and in six $(28.6 \%)$ of the 21 surviving patients with PEM. The odds ratio (odds ratio $=(3 / 1) /(6 / 15)=7.5)$ for mortality was 7.5 times higher in the malnourished children with hypomagnesaemia $(n=9)$ than in the malnourished children without hypomagnesaemia $(n=16)$. When the mean weight-for-height measurements of the deceased and the surviving patients were evaluated, no significant difference ( $>0.05$ ) was observed between them.

We found significant differences in serum $\mathrm{Mg}$ levels but not in serum ET-1 levels between the surviving and the deceased groups of patients with PEM. Serum $\mathrm{Mg}$ levels were significantly lower in the paediatric patients (68.8\%) in the intensive care unit compared to the control group $(12.0 \%)(\mathrm{p}<0.001)$ (4). Furthermore, Mg intake from drinking-water was suggested to exert a significant protective effect on the risk of cerebrovascular disease and death from stroke (5). $\mathrm{Mg}$ is one of the most abundant ions in human cells, and its serum concentration is remarkably constant in healthy subjects. Although the measurement of serum Mg does not always reflect the overall status of $\mathrm{Mg}$ metabolism, serum $\mathrm{Mg}$ correlates well with intracellular-free $\mathrm{Mg}$, the physiological active form of the elements (6). However, even small alteration in the extracellular $\mathrm{Mg}$ concentration can influence human organism and metabolism.

When ET-1 levels were investigated as a mortality risk factor, Kunz et al. reported that plasma ET-1 levels were slightly higher but not significant in haemodialyzed patients with cardiovascular history compared to haemodialyzed patients without cardiovascular history (7). Adversly, plasma ET-1 concentrations are strongly related to outcome af- 


\begin{tabular}{|c|c|c|c|}
\hline Parameter & $\begin{array}{l}\text { Surviving patients } \\
\qquad(\mathrm{n}=21)\end{array}$ & $\begin{array}{c}\text { Deceased } \\
\text { patients } \\
(\mathrm{n}=4)\end{array}$ & $\mathrm{p}$ value \\
\hline $\mathrm{Mg}(\mathrm{mg} / \mathrm{dL})$ & $2,06 \pm 0,33$ & $1,55 \pm 0,43$ & $<0.05$ \\
\hline ET-1 (pg/mL) & $42,23 \pm 14,81$ & $45,17 \pm 13,95$ & $>0.05$ \\
\hline
\end{tabular}

ter acute myocardial infarction $(\mathrm{p}<0.0001)$ and provide prognostic information independent of clinical and biochemical variables. On the other hand, an experimental study showed that magnesium deficiency was associated with increased ET-1 levels and with significant proaggregatory and coagulation alterations (8). When Serebruany et al. investigated alterations in various haemostatic factors as risk factors for survival after acute myocardial infarction (9), no significant differences was found in the ET-1 plasma concentrations during occlusion between the surviving and the non-surviving groups in this study, although plasma baseline ET-1 levels was slightly higher but not significant in the deceased swine (9). This result was similar to ours. However, results of a previous study showed that the mean serum ET-1 levels in the group with low magnesium levels were significantly higher than that of the group with normal magnesium levels $(\mathrm{p}<0.05)$ in malnourished children (10). This discrepancy in our results may be related to the low number of the deceased patients with PEM. On the other hand, it has been shown a release of TNFa and IL-1 at approximately one week after the administration of a low $\mathrm{Mg}$ diet in mice (11). Results of another study showed that hypomagnesaemia could stimulate endothelial cells to produce and release ET-1 (12). So, the sampling time may be also important.

Since the number of cases chosen was small in our study, additional studies on pathophysiology and clinical importance of hypomagnesaemia are needed. The findings of the present study calls for giving attention to hypomagnesaemia as a mortality risk factor in PEM.

\section{REFERENCES}

1. Amsalu S, Asnakew G. The outcome of severe malnutrition in northwest Ethiopia: retrospective analysis of admissions. Ethiop Med J 2006;44:151-7.

2. Shivakumar K. Model of cardiovascular injury in magnesium deficiency. Med Hypotheses 2001;56:1103.

3. Yanagisawa M, Kurihara H, Kimura S, Tomobe Y, Kobayashi M, Mitsui Y et al. A novel potent vasoconstrictor peptide produced by vascular endothelial cells. Nature 1988;332:411-5.
4. Deshmukh CT, Rane SA, Gurav MN. Hypomagnesaemia in paediatric population in an intensive care unit 2. J Postgrad Med 2000;46:179-80.

5. Yang CY. Calcium and magnesium in drinking water and risk of death from cerebrovascular disease. Stroke 1998;29:411-4.

6. Seelig M. Cardiovascular consequences of magnesium deficiency and loss: pathogenesis, prevalence and manifestations: magnesium and chloride loss in refractory potassium repletion. Am J Cardiol 1989;63:421.

7. Kunz K, Petitjean P, Lisri M, Chantrel F, Koehl C, Wiesel ML et al. Cardiovascular morbidity and endothelial dysfunction in chronic haemodialysis patients: is homocyst(e)ine the missing link? Nephrol Dial Transplant 1999;14:1934-42.

8. Serebruany VL, Herzog WR, Edenbaum LR, Shustov AR, Gurbel PA. Changes in the haemostatic profile during magnesium deficiency in swine. Magnes Res 1996;9:155-63.

9. Serebruany VL, Solomon SR, Shustov AR, Herzog WR, Gurbel PA. Survival in acute myocardial infarction induced by coronary ligation: prognostic relevance of certain hemostatic factors during the occlusion phase. J Thromb Thrombolysis 1998;5:29-35.

10. Ozturk C, Karakelleoglu C, Orbak Z, Yildiz L. The effect of serum $\mathrm{Mg}$ levels on bone mineral density and serum endothelin-1 levels in protein energy malnutrition. Horm Res 2007;68(Suppl 1):65.

11. Weglicki WB, Dickens BF, Wagner TL, Chemielinska JJ, Phillips TM. Immunoregulation by neuropeptides in magnesium deficiency: ex vivo effect of enhanced substance $P$ production on circulation T lymphocytes from magnesium-deficient mice. Manges Res 1996;9:311.

12. Weglicki WB, Phillips TM, Freedman AM, Cassidy MM, Dickens BF. Magnesium-deficiency elevates circulating levels of inflammatory cytokines and endothelin. Mol Cell Biochem 1992;110:169-73.

\section{Cahit Karakelleoglu', Zerrin Orbak',2, Candan Ferai Ozturk', and Celalettin Kosan'

\footnotetext{
'Department of Pediatrics and ${ }^{2}$ Department of Pediatric Endocrinology and Metabolism, Atatürk University Faculty of Medicine, Erzurum, Turkey
} 